\title{
Supervisor-Subordinate Relationship Conflict Asymmetry and Subordinate Turnover Intentions: The Mediating Roles of Stress and Counterproductive Work Behaviors
}

\author{
C. Justice Tillman \\ Baruch College \\ Anthony C. Hood \\ University of Alabama at Birmingham \\ Orlando C. Richard \\ University of Texas at Dallas
}

\begin{abstract}
Research on employee turnover suggests that divergent perceptions of relationship conflict between supervisors and subordinates may motivate voluntary turnover. However, despite evidence of asymmetric perceptions of conflict within groups, little research has examined the effects of conflict asymmetry between supervisors and subordinates on behavioral outcomes. Drawing on a sample of 178 supervisor-subordinate dyads, we test whether subordinate turnover intentions are associated with the relationship conflict asymmetry. We further examine subordinate stress and counterproductive work behaviors directed towards supervisors as mediators of this relationship. Implications for practice and future research are elaborated.
\end{abstract}

Keywords: Turnover, Counterproductive Work Behaviors, Conflict Asymmetry

\section{Introduction}

Conflict is a costly, yet inescapable aspect of work relationships. Extant research describes conflicts as workplace stressors which are "environmental factors at work that lead to individual strains - aversive and potentially harmful reactions of the individual" (Beehr, Jex, Stacy \& Murray, 2000, p. 391). The strains caused by conflict may manifest as negative affective (e.g. dissatisfaction), behavioral (e.g. counterproductivity), physical (e.g. illness) or psychological (e.g. distress) reactions (Spector \& Jex, 1998). Research has tended to highlight three forms of conflict - task, process, and relationship (De Wit, Greer \& Jehn, 2012). Task conflicts are disagreements involving strategies, methods, and opinions, while process conflicts encompass disputes over divisions of labor, responsibilities, and procedures (De Wit et al., 2012). Relationship conflict, recognized as the most harmful, reflects differences stemming from differences in values, ideologies, personal preferences, and temperaments (Jehn, 1995; Jehn $\&$ Bendersky, 2003) and has been associated with a range of negative employee outcomes including decreased job satisfaction, performance, and commitment (De Wit et al., 2012), 
increased stress (De Dreu \& Weingart, 2003), and increased counterproductive work behaviors (Rispens, Greer, Jehn, \& Thatcher, 2011).

Traditionally, studies of intragroup conflicts (e.g. Jehn, 1995) address group member perceptions of the amount of conflict occurring among group members (whether or not the focal individual is personally involved in the conflict), whereas treatments of interpersonal conflict typically include individuals' self-perceptions of conflict occurring between themselves and specific other individuals (e.g. Frone, 2000). Compared to the significant amount of research on intragroup relationship conflicts (De wit et al., 2012), fewer studies have explored interpersonal relationship conflicts between supervisors and their subordinates, or the impact of such stressful conditions on subordinate outcomes. Further, when supervisor-subordinate conflicts are studied, conflict is often assessed from the perspective of only one member of the dyad (e.g. Kacmar, Bachrach, Harris, \& Noble, 2012; Landry \& Vandenberghe, 2009; Xin \& Pelled, 2003), often raising concerns of common method bias (Podsakoff, MacKenzie, Lee \& Podsakoff, 2003). Not surprising then, empirical studies of self-other agreement of relationship conflict between supervisors and subordinates, or what Jehn, Rispens, and Thatcher (2010) refer to as relationship conflict asymmetry (RCA), has yet to be explored. Although RCA has been examined in the context of intragroup relationships (Jehn et al., 2010), RCA has not been explored in the context of supervisor-subordinate dyads. This is an important omission for several reasons.

First, previous research on self-other agreement suggests that perceptual asymmetries, particularly those occurring between supervisors and subordinates, generate adverse consequences for employees (Atwater \& Yammarino, 1997; Cogliser, Schriesheim, Scandura, \& Gardner, 2009). For example, the leader-member exchange (LMX) balance framework suggests that, relative to their supervisors, subordinates may misjudge the quality of their relationship with a supervisor such that a subordinate may overinflate his/her standing with the supervisor or underestimate the likelihood of threatening or adverse circumstances (Cogliser et al., 2009). This research demonstrates that subordinates' miscalculation of relationship quality may negatively impact subordinates' job performance, job satisfaction and organizational commitment (Cogliser et al., 2009). Although the LMX balance framework highlights the consequences of the mere presence of perceptual disagreement (i.e. over or underestimation), the magnitude of perceptual disagreement (e.g. how much over or under) requires further exploration.

Second, although the emerging conflict asymmetry paradigm has linked intragroup conflict perceptions to group member outcomes including satisfaction, performance, commitment, respect, trust, communication, and cooperation (Jehn et al., 2010), missing thus far has been examination of associations between supervisor-subordinate conflict asymmetry and subordinate turnover intentions. Previous research suggests that the quality of supervisorsubordinate relationships drive subordinate turnover intentions (Dulebohn, Bommer, Liden, Brouer, \& Ferris, 2011). Supervisor-subordinate RCA is likely to contribute to subordinate turnover intentions by causing unequal and unreciprocated resource investments in the supervisor-subordinate relationship. Research on employee turnover suggests that one of the motivational drivers of turnover is related to the fulfillment of psychological contracts and mutual obligations between employees and their organizations and agents (Maertz \& Griffeth, 2004; Morrison \& Robinson, 1997). Theories such as social exchange (Gouldner, 1960) and conservation of resources (Hobfoll, 1989) suggest that subordinates invest resources in the work 
context with the expectation of future equal or positive returns on investment (ROI). We posit that perception drives resource investment such that perceptual differences lead to an imbalance in resources necessary to address the concerns of those involved in conflict. Thus, subordinates who overinvest in conflict relative to their supervisors may be subject to negative returns on investment and subsequent increased consideration of whether the costs of remaining with the organization outweigh the benefits of remaining (Maertz \& Griffeth, 2004).

With this focus, we seek to make a number of distinct contributions. First, drawing on and integrating previous research on leadership, conflict asymmetry and self-other agreement (Atwater \& Yammarino, 1997; Cogliser et al., 2009), we introduce the concept of supervisorsubordinate RCA and investigate its impact on three subordinate outcomes of conflict: felt job stress, counterproductive work behavior towards a supervisor (CWB-I) and turnover intentions. Figure 1 depicts these conceptual relationships we discuss in further detail below and propose in our hypothesized model.

Our decision to focus on these outcomes was driven by organizational stress theory (Hobfoll, 1989) which positions the outcomes of workplace stressors as strains, or negative reactions to stressful conditions such as conflict. Further, these factors respond to calls for future investigations of the workplace stressor-strain-turnover pathway (e.g. de Croon, Sluiter, Blonk, Broersen, \& Frings-Dresen, 2004). Second, we add nuance to current understanding of how the supervisor-subordinate relationship drives subordinate turnover intentions (Dulebohn, et al., 2011). Following intragroup conflict asymmetry theory, we expect that the magnitude of RCA between supervisors and subordinates will explain variance in subordinate outcomes beyond that explained by mean levels alone (Jehn et al., 2010). This focus also reflects De Dreu and Weingart's (2003) call for research to explore the mechanisms driving the association between relationship conflict and turnover.

\section{Theory and Hypotheses}

\section{Conservation of Resources Theory}

The underlying theme of the current study is grounded in organizational resource and motivation theories, in particular, the general motivational theory of conservation of resources (COR; Hobfoll, 1989). According to COR, employee perceptions of and experience with their environment motivates the "accumulation, protection, investment and replenishment of personal resources" (Wheeler, Harris, \& Sablynski, 2012; E244). Personal resources include time, attention, face, energy and anything else of value to an individual (Halbesleben, Harvey \& Bolino, 2009; Hobfoll, 1989). When faced with resource threats, individuals are motivated to invest their available personal resources to avoid a net loss of resources. As resource depletion outpaces resource replenishment or accumulation, individuals may exhibit a range of negative reactions (i.e. strain) including emotional exhaustion and burnout (Halbesleben \& Bowler, 2007), counterproductive work behavior (Penney, Hunter \& Perry, 2011) and organizational withdrawal (Sliter, Sliter \& Jex, 2012). However, in times of resource security and abundance, individuals are motivated to invest their personal resources to broaden and build their current resource stocks (Halbesleben \& Bowler, 2007). In the following sections, each construct is defined, and the relationships among the constructs are individually examined as they relate to the framework. 


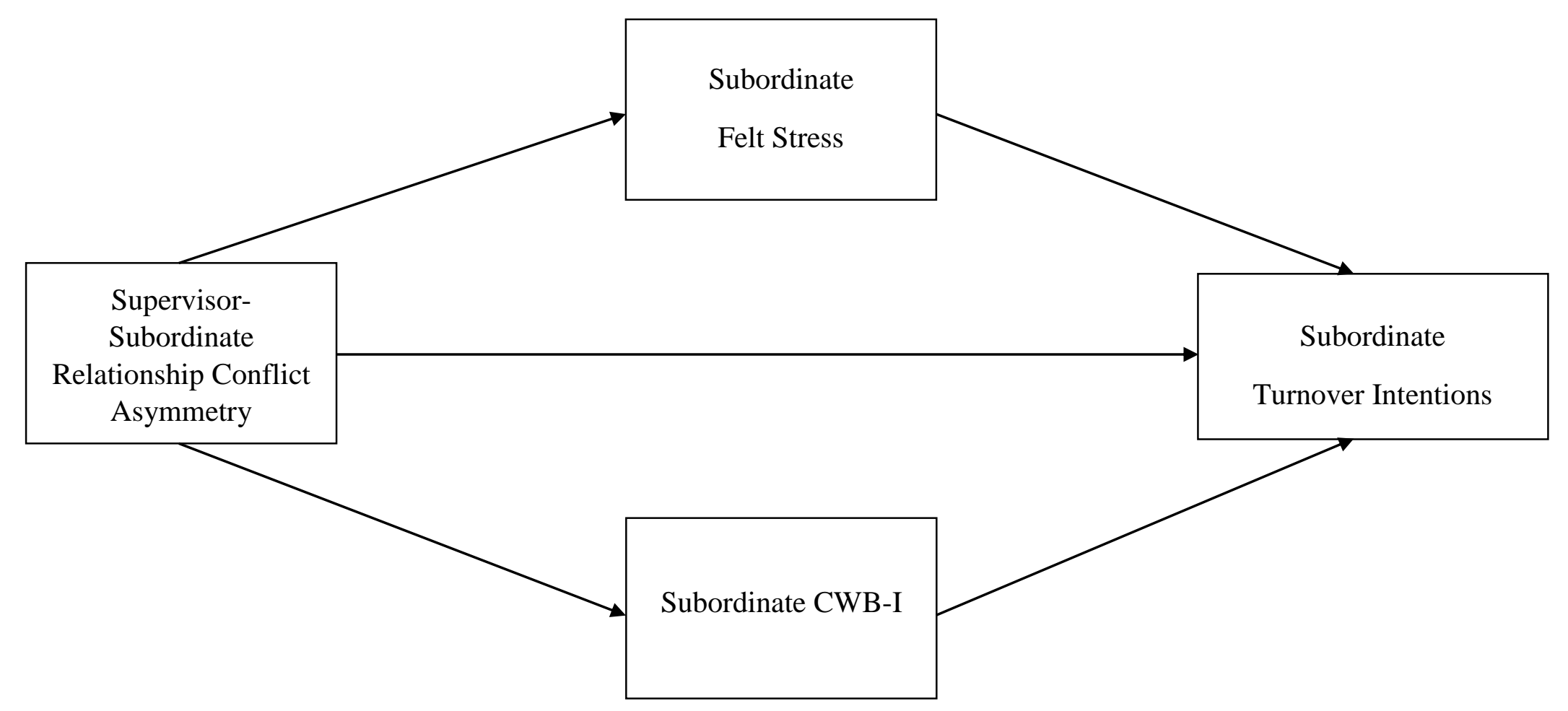

Figure 1. Hypothesized Model 


\section{Relationship Conflict}

Consistent with previous research (LePine, Podsakoff, \& LePiine, 2005; Spector \& Jex, 1998), we consider conflict to be in line with other workplace stressors such as job demands and job control (de Croon et al., 2004). Relationship conflict may occur among people with different value systems, political ideologies, personalities or orientations (Jehn, 1995). Although conflict may be associated with negative reactions such as stress, we consider conflict to be distinct from stress. We consider strain to be a negative response to stressful conditions which may manifest as felt job stress, counterproductive behavior, or increased turnover intentions (Hunter \& Thatcher, 2007; Van Dyne, Jehn \& Cummings, 2002).

Process models of conflict indicate that conflict emerges episodically, under latent conditions of interdependence, resource scarcity, and power asymmetry (Deutsch, 1949; Pondy, 1967). Conflict is triggered when individuals perceive that their interests, values, or preferences are incompatible with others' (Jehn, 1995). This perception initiates a sense-making process of appraisal regarding the extent that a situation violates perceived obligations or expectations, as well as assignment of responsibility for violations (Korsgaard, Soyoung Jeong, Mahony, \& Pitariu, 2008).

Although the majority of research on organizational conflict has focused at the intragroup level (De Dreu \& Weingart, 2003; De Wit et al., 2012), recent focus has begun to explore interpersonal conflicts, particularly those occurring among supervisors and subordinates (Frone, 2000; Kacmar et al., 2009; Ismail, Richard, \& Taylor, 2012). Conflicts between supervisors and subordinates, or vertical dyadic conflicts, occur when employees and their supervisors become aware of disagreements, tension or difficulties between them. Previous research has demonstrated that employee conflicts with supervisors (vertical conflicts) are distinguishable from conflicts with coworkers (horizontal conflicts) and are differentially predictive of organizationally- and personally-relevant outcomes (Frone, 2000). For example, in a study of working students, Frone (2000) found that interpersonal conflicts with supervisors were related to organizationally-related outcomes such as subordinate job satisfaction, organizational commitment and turnover intentions whereas conflicts with coworkers were related to personally-related outcomes such as subordinate depression, self-esteem and somatic symptoms.

In a study of 160 supervisor-subordinate dyads, Kacmar and colleagues found that vertical dyadic relationship conflicts were negatively related to subordinates' demonstration of organizational citizenship behaviors (OCB) (Kacmar et al., 2012). On the basis of social exchange theory (Blau, 1964), the authors reasoned that resource contributions between supervisors and subordinates create diffuse obligations to repay on the part of recipients. Subordinates typically expect their organizations and its supervisors to provide a safe and positive work environment (Organ, 1990). Subordinates who perceive positive organizational experiences are compelled to reciprocate by investing their personal resources (time, attention for the benefit of the organization and its agents. Additionally, subordinate investments are often made with an expectation of future repayment and continued mutual exchange (Kacmar et al., 2012). However, negative workplace experiences such as relationship conflicts interfere with social exchanges by leading subordinates to perceive that the organization has not met their obligations. As a result, relationship conflicts with supervisors may cause subordinates to 
perceive they have no debt to repay (Kacmar et al., 2012). Conversely, research on intragroup conflict suggests that relationship conflicts may motivate the enactment of negative, retaliatory behaviors (Rispens et al., 2011). Employees who feel threatened or harmed by others may repay the sentiments by withholding effort, avoiding interaction or blocking the interests of offending parties (Rispens et al., 2011). These responses are consistent with COR which suggests that employees respond to perceived resource threats or losses by investing personal resources (Hobfoll, 1989). In this way, subordinate perceptions drive the level and direction (i.e. productive or counterproductive) of subordinate investment.

The notion that supervisor-subordinate relationship conflicts motivate investments has consequences for employee turnover intentions. For example, Ismail and colleagues (2012) argued that the positive association between supervisor-subordinate relationship conflicts and subordinate turnover intentions are influenced by subordinate cost-benefit ratio perceptions. Subordinates' intent to turnover becomes more likely as the costs of staying exceed the benefits of staying. Relationship conflicts with supervisors may reduce the favorability of these ratios leading to reduced commitment and increased withdrawal.

In a study of the relationships between 72 supervisors participating in a university-based management development program and their direct reports, Xin \& Pelled (2003) found that supervisors' perceptions of emotional conflict (i.e. relationship conflict) had a stronger negative association with subordinates' perceptions of supervisor behavior (i.e. emotional support and creativity encouragement) than did mixed conflict (both emotional and task conflict). Specifically, subordinates in relationship conflict with their supervisors are less likely to feel that their supervisors have faith in their abilities or are encouraging of innovative thought (Xin \& Pelled, 2003). As a consequence, emotional conflicts "make it difficult for subordinates to respect their supervisors and evaluate them favorably" (Xin \& Pelled, 2003; 36).

\section{Relationship Conflict Asymmetry}

Given demonstrated associations in previous studies between the level of relationship conflict perceived by employees and their intentions to turnover (e.g. Frone, 2000; Ismail et al., 2010) we offer no formal hypothesis to this effect. Instead, the purpose of the current study is to explore the explanatory power of relationship conflict asymmetry beyond that of average levels of relationship conflict. This aim is guided by directions offered by Jehn and colleagues (2010) who, in their study of individual and group conflict asymmetry, implore conflict researchers to "...not only consider the mean level of conflict, as in past research (e.g. Amason, 1996; De Dreu \& Weingart, 2003; Jehn, 1995), but also conflict asymmetry concepts framed at both the individual and group levels" (Jehn et al., 2010, p. 608). The authors found individual conflict asymmetry to be predictive of satisfaction with a team and self-rated performance when controlling for mean levels of conflict in the team, suggesting that average levels of conflict alone may be insufficient to explain the true impact of conflict on key individual outcomes. In addition, their study highlights the importance of individual direction (i.e. perceiving more or less conflict than others) in the study of conflict asymmetry.

A recent study by Cogliser and colleagues investigated the impact of supervisor and subordinate perceptual agreement of LMX quality on job performance, job satisfaction and 
organizational commitment. The authors drew upon the self-other agreement framework advanced by Atwater and Yammarino (1997; Yammarino \& Atwater, 1997) to advance what they refer to as the LMX balance framework. According to the LMX balance framework, supervisor-subordinate relationships may be categorized based on agreement (balanced/low or balanced/high) or disagreement (subordinate over- or under-estimation). Balanced/high LMX relationships refer to symmetric perceptions of high quality supervisor-subordinate relations whereas balanced/low LMX relationships refer to symmetric perceptions of low quality supervisor-subordinate relations. Unbalanced LMX perceptions were characterized as subordinate overestimation (subordinate perceives the relationship as high quality whereas the supervisor perceives a low quality relationship) and subordinate underestimation (subordinate considers the relationship to be low quality whereas the supervisor perceives it be high).

The current study differs from this research in several ways. First, the focus of the LMX balance framework is on the simple existence of agreement/imbalance rather than the magnitude of agreement. As a result, the framework is silent regarding whether increases or decreases in over-or under-estimation explain variance in subordinate outcomes. Second, our focus is not on which category of asymmetry (symmetric high, symmetric low, low/high or high/low) is most predictive of subordinate outcomes. Moreover, we follow intragroup conflict asymmetry research which suggests that asymmetry explains variance in outcomes beyond that explained by average levels alone. We hypothesize that the magnitude of the perceptual asymmetry between supervisors and subordinates contribute to greater resource investment discrepancies which lead ultimately to unfavorable subordinate responses.

Resource investments in response to relationship conflict are likely determined by the extent that opposing parties have differing perceptions of the extent of relationship conflict. For example, Jehn et al. (2010) reported that high perceivers, or individuals who overestimate relationship conflict relative to their group members, tend to be less satisfied with their groupsa dissatisfaction that may be caused by perceived resource imbalances. These authors argued, "the person who perceives more conflict than others is likely to spend his/her time and energy discussing, resolving, or ignoring the perceived conflict, rather than on performance-relevant tasks" (Jehn et al., 2010, p. 600). In contrast, low perceivers, or individuals who underestimate conflict relative to others, may have a more optimistic view of reality than they should. Due to their bias towards positivity, low perceivers tend to experience more satisfaction, performance, and success (Jehn et al., 2010; Murray, Holmes, \& Griffin, 1996). Low perceivers also are more motivated and persistent regarding their work (Felson, 1984). As a result, low perceivers may be more likely to perceive a net positive return on their prior resource investments than high perceivers.

According to conflict asymmetry research, the notion that different parties can have differing perceptions of relationship conflict between them may be more important for understanding the consequences of relationship conflict than average levels alone (Jehn et al., 2010). For example, Jehn et al. (2010) found that, controlling for average levels of conflict between parties, individuals who perceived more conflict than others were less satisfied than individuals who perceived less conflict than others. However, when parties agree on the amount of incompatibility between them, even if they agree on a high level, they may be better equipped to avoid sensitive topics and maintain an otherwise productive arrangement (Jehn et al., 2010). 
This perceptual agreement may be indicative of balanced resource contributions between conflicting parties that help them to avoid further escalation of conflict. Consistent with this perspective in the current study, we were more focused on the impact of supervisor-subordinate conflict asymmetry on subordinate outcomes regardless of the overall amount of conflict perceived by the parties.

\section{COR and Turnover Intentions}

As a general motivation theory, the COR perspective leveraged in the current paper is consistent with motivational theories of turnover. For example, in a recent review of the research on turnover, Maertz and Griffeth (2004) identified eight motivational drivers of turnover (e.g. affective, calculative, contractual, behavioral, alternative, normative, moral/ethical and constituent) of which four (affective, calculative, contractual, and behavioral) are relevant to the current investigation. Affective forces include individuals' tendency to approach situations offering comfort or pleasure and to avoid those that cause discomfort or pain. Employees experiencing psychological discomfort with their organization will be motivated to avoid or reduce these undesirable conditions. Conversely, employees that feel good towards their organizations will be motivated to maintain and seek more of these favorable conditions.

Calculative forces refer to cognitive estimations regarding the likelihood of achieving desired outcomes and future objectives given continued affiliation with the organization. Positive valuations will compel one to remain, while negative valuations will compel one to resign. Contractual forces refer to perceived obligations and performance on the part of employees and the organization that create psychological contracts regarding expectations of exchange between parties (Robinson \& Morrison, 2000). An employee perceives a psychological breach of contract when the employee fails to receive what he/she believes the organization is obligated to provide (Morrison \& Robinson, 1997). As noted by Maetrz and Griffeth (2004) concerning an employee who perceives a psychological breach: "the employee may perceive a betrayal and feel obligated to "even the score" or strike back at the organization by quitting" (p. 672). Employing psychological contracts logic, Ismail et al. (2012) argue that supervisors and subordinates develop unwritten expectations regarding the reciprocal exchanges required from one another to maintain a healthy relationship. If the costs associated with these exchanges outweigh the benefits, then subordinates will become psychologically withdrawn and will increase intentions to quit. In contrast, when cost-benefit ratios are favorable, then subordinates will be more psychologically attached and be more committed to staying. As we note below, in addition to quitting, betrayed employees may seek retribution by blocking or sabotaging the interests of their organizations (Greenberg, 1990). Finally, behavioral forces refer to the perceived costs related to staying with or exiting the organization. For employees experiencing discomfort or conflict with their supervisors, the costs associated with staying with the organization may outweigh the costs of leaving. As such, "staying implies psychological costs that can be reduced by quitting" (Maertz \& Griffeth, 2004; p. 673).

\section{Relationship Conflict Asymmetry and Turnover Intentions}

Conflict poses a threat to available resources as well as to potential resources otherwise available through relationships with conflicting parties (Hobfoll, 1989). When conflict is 
perceived to be non-existent (e.g., complete harmony and compatibility), individuals devote little or no time, attention, or energy resources to addressing conflict. However, when conflict perceptions increase in frequency, severity, or intensity, the resources devoted to detecting, avoiding, minimizing, resolving, or recovering from conflict also increases (Grandey \& Cropanzano, 1999). Thus, perceived conflict serves as a cue that action is needed. In response, individuals will invest resources towards the prevention or resolution of conflict to minimize actual or potential resource losses (Hobfoll, 1989).

The resources expended acknowledging, avoiding, or resolving conflict is influenced by the amount of conflict perceived (Jehn et al., 2010). Variance (or asymmetry) in conflict perceptions is likely to be associated with variation in the amount of time, attention, and energy conflicting parties deem necessary to address the conflict. Although relationship conflict is difficult, subordinates are likely to take comfort when supervisors 'adequately' acknowledge their differences (as opposed to downplaying their significance). As noted by Xin and Pelled (2003), vertical relationship conflicts leave subordinates feeling unsupported and unencouraged by their supervisors. Subordinates will thus likely devote fewer resources to the relationship and more to their core work requirements. However, when supervisors are similarly aware of subordinates' concerns and grievances, they may be able to avoid further escalation of conflict by matching the level and kind of resources contributed by their subordinates.

Additionally, a subordinate could realize less conflict with their supervisor on the one hand or more conflict with their supervisor on the other hand. These differences will create unequal resource contributions from the supervisor and the subordinate; subordinates who invest more resources than their supervisors will perceive an inadequate return on their investment (ROI), whereas those who contribute less will perceive a positive ROI (Hobfoll, 1989). Subordinates perceiving a negative ROI will be motivated to reduce this condition by developing intentions to exit the organization (Maertz \& Griffeth, 2004). We therefore hypothesize: ${ }^{1}$

\section{Hypothesis 1: Subordinates who perceive more supervisor-subordinate relationship conflict than their supervisors (i.e., RCA) exhibit higher turnover intentions than subordinates who perceive less supervisor-subordinate relationship conflict than their supervisors, regardless of the mean level of relationship conflict in the supervisor- subordinate dyad.}

\section{The Mediating Role of Stress}

Research has suggested the links from workplace stressors and turnover follow a mediated pathway through strain (de Croon et al., 2004). We consider relationship conflict to be a stressor, whereas we consider felt stress to be a psychological strain (Beehr et al., 2000). COR describes felt stress as a psychological response to an environment in which there is a perceived or actual loss of resources or an unrealized gain from a prior resource investment (Hobfoll, 1989). In essence, stress is a consequence of a psychological calculation regarding the extent that resource surpluses and gains are insufficient to adequately address resource threats, losses, or

\footnotetext{
${ }^{1}$ All analysis completed controlling for mean level of relationship conflict. Harrison and Klein (2007) indicate that the mean level of a variable needs to be controlled when examining asymmetry variables in order to prevent each variable from being confounded by the other.
} 
investments (Hobfoll, 1989). Because the supervisor-subordinate relationship serves as a primary conduit through which social resources flow to and from both parties, (Organ, 1990) supervisor-subordinate conflicts pose a threat to: a) subordinates' current resources, b) the ongoing relationship between the supervisor and subordinate, and c) any future resources available through this relationship. To cope with resource losses or threats, both parties are likely to make resource investments in accordance with the amount of conflict perceived. Individuals that perceive high levels of conflict are likely to respond by making large resource expenditures and vice versa.

Because perceptions of relationship conflict cue action to avoid, minimize, or recover from resource loss (Staw, Sandelands, \& Dutton,, 1981), high conflict perceivers will expend more resources to resolve relationship conflict than low perceivers. Subordinates who overinvest in relationship conflict relative to their supervisors will experience strain due to a perceived unrealized gain from the resources invested (Hobfoll, 1989). Low perceiving supervisors are more likely to reach false consensus in which they mistakenly believe that they have adequately addressed subordinates' concerns. During conflict resolution discussions, low perceiving supervisors may prematurely disengage from the conversation, leaving subordinates with unresolved concerns. Hastily dismissed or undetected conflicts are unlikely to be resolved to subordinates' satisfaction. Responses offered by low perceiving supervisors are likely to be delayed or weak, if given at all, causing resentment, disrespect, and feelings of invalidation in their higher perceiving subordinates (Jehn et al., 2010).

In contrast, lower perceiving subordinates are likely to experience less negative reactions in response to supervisors' 'adequate' reciprocation of the relationship conflict. Higher perceiving supervisors are better positioned to avoid sensitive topics that trigger personal debates and foster negativity with subordinates. When subordinate perceptions of relationship conflict are matched, or exceeded by supervisors, subordinates are more likely to feel validated and respected. This leads subordinates to perceive a positive return on investments made to address conflict. When subordinates perceive more conflict than their supervisors, they are more likely to perceive a net loss of resources, leading to increased feelings of stress.

Hypothesis 2a: Subordinates who perceive more RCA than their supervisors (i.e., conflict asymmetry) experience more felt stress than subordinates who perceive less supervisorsubordinate relationship conflict than their supervisors, regardless of mean levels of relationship conflict in the supervisor-subordinate dyad.

As a result of the felt stress caused by resource concerns, high perceiving subordinates may begin to question the likelihood of achieving their personal goals through continued relationship with their supervisor and organization. Because felt stress increases the costs of relational and organizational attachment, subordinates will be motivated to avoid these costs by entertaining the option of voluntarily exiting the organization (Boswell, Olson-Buchanan, \& LePine, 2004; Maertz \& Griffeth, 2004). As a consequence, high perceivers will be motivated to alleviate losses through leaving their relationship with their supervisors and their organizations, leading to the following:

Hypothesis 2b: Subordinate stress will be positively related to turnover intentions. 
Hypothesis 2c: Subordinate stress mediates the effect of RCA on subordinate turnover intentions. Specifically, subordinates who perceive higher levels of supervisor-subordinate relationship conflict than their supervisors are more likely to experience higher stress, and they are therefore more likely to exhibit higher turnover intentions.

\section{The Mediating Role of Counterproductive Work Behaviors}

Supervisors that perceive less conflict than their subordinates may be seen as aloof, inattentive, and unsympathetic to the concerns of their higher perceiving partners. These subordinate perceptions may cause supervisors to be a target of deviant behavior (Carver \& Jones, 2009). High perceiving subordinates are more likely to perceive lower perceiving supervisors as being in violation of their obligation to provide subordinates with proper respect, care, and validation (Organ, 1990). Perceived violations are accompanied by strongly negative feelings of betrayal and resentment that influence a wronged party to regain relational equilibrium with the perpetrator (Carver \& Jones, 2009; Morrison \& Robinson, 1997). Conflict asymmetries can develop into more enduring patterns of negative interaction such that a higher perceiver may intentionally harm or block the interests of the lower perceiver, regardless of mean perceived conflict (Labianca \& Brass, 2006). Subordinates that intentionally harm the interests of their supervisors increase the likelihood of retribution (Maertz \& Griffeth, 2004). Consistent with behavioral drivers of turnover, fears regarding supervisor retaliation or organizational reprimand increase the psychological costs of staying and serve as a motivator to quit.

Thus, we expect that the associations between supervisor-subordinate RCA and subordinate turnover intentions are mediated by supervisor-focused counterproductive work behaviors. As a subordinate's perceptions of relationship conflict exceed those of their supervisor, the subordinate will seek to re-establish relational equilibrium with their supervisor due to the supervisor's failure to reciprocate the care and consideration invested by the subordinate. Subordinates' negative reactions to their supervisors' apparent inattention or unresponsiveness leads subordinates to assess the costs of staying as outweighing the benefits of staying. We therefore hypothesize the following:

Hypothesis 3a: Subordinates who perceive more supervisor-subordinate relationship conflict than their supervisors (i.e., RCA) engage in more counterproductive work behaviors directed towards their supervisors than subordinates that perceive less supervisor-subordinate relationship conflict than their supervisors, controlling the mean level of relationship conflict in the supervisor-subordinate dyad.

Hypothesis 3b: Subordinates who engage in more counterproductive work behaviors directed towards their supervisors exhibit higher turnover intentions.

Hypothesis 3c: Subordinate counterproductive work behaviors directed towards supervisors mediates the relationship between supervisor-subordinate RCA and subordinate turnover intentions. Specifically, subordinates who perceive higher levels of supervisor-subordinate relationship conflict than their supervisors are more likely to 
engage to counterproductive work behaviors directed towards their supervisors, and they are therefore more likely to exhibit higher turnover intentions.

\section{Method}

\section{Data and Sample}

Data were collected from graduate students at a U.S. university as well as their direct supervisors at work. Employed students are considered a reliable data source and results generated from scientifically designed studies based on working student samples are generalizable to other groups and populations (Croson \& Donhue, 2006; Milliken, 1990). Participants were employed in an array of functional areas and worked in a variety of industries. Hence, the potential homogeneity of the respondent pool does not appear to be a serious concern (Scandura \& Williams, 2000). Furthermore, more than one data source (data were collected from both the subordinates and their direct supervisors) was used to increase external validity of the current study (Rosenthal \& Rosnow, 2006) and to minimize common method variance concerns. (Podsakoff et al., 2003).

Invitations were offered to students (who were asked to fill out the subordinate survey) and their direct supervisors (who were asked to fill out the supervisor survey) regarding interview schedules and survey procedures. Participation was voluntary ${ }^{2}$. Each supervisor provided no more than one survey for the current study. The supervisor survey was sealed and signed across the seal by the supervisor and delivered directly to the first author. Supervisor contact information was requested voluntarily in the survey to allow for random checks for true submissions, which increases the authenticity of the data collected. Students were awarded extra credit for the completion of the subordinate and supervisor surveys.

Each survey included a cover page explaining the purpose and procedures of the study and a questionnaire containing instructions, construct items, and scales. The subordinate survey and supervisor survey were matched using an identification code generated by the student participant to ensure confidentiality (Tepper \& Taylor, 2003). A total of 178 matched supervisorsubordinate surveys were collected, yielding a response rate of 26.1 percent for the sampling frame. The final sample included employees from a broad cross-section of industries, including manufacturing $(17.9 \%)$, wholesaling $(3.4 \%)$, retailing $(7.9 \%)$, services $(42.7 \%)$, healthcare $(6.7 \%)$, government and education $(12.9 \%)$, and other $(8.4 \%)$. Of the respondents, 61.8 percent were male and the average age was 26 years (range 18 to 59 years). Subordinates span a number of racial backgrounds including White (42.7\%), Asian (46\%), Hispanic (6.2\%), African American (3.4\%), and Other (1.7\%). Supervisors also came from varied racial backgrounds, including White (64\%), Asian (16\%), American Indian (2.2\%), Hispanic (6.7\%), African American (7.3\%), and Other (3.4\%).

\footnotetext{
${ }^{2}$ To assure confidentiality, employee participants were asked to check in via a sign-up sheet at a location different from where the survey was being administered and without the presence of the researcher. Their bonus credits were later given based on the sign-up sheet.
} 


\section{Measures}

Subordinate turnover intentions. Subordinate turnover intentions were measured using Begley and Czajka's (1993) two-item scale (1 = strongly disagree to $5=$ strongly agree $)$. These two items are "As soon as I find a better job, I'll quit" and "I often think about quitting my current job". Cronbach's alpha for this scale was .81.

Relationship conflict asymmetry. Relationship conflict within the supervisorsubordinate dyad was measured using an adapted version of Jehn's (1995) four-item intragroup relationship conflict scale $(1=$ strongly disagree to $5=$ strongly agree $)$. Supervisors and subordinates were asked the same questions regarding relationship conflict within the supervisorsubordinate dyad. Sample items included "My supervisor (subordinate) and I experience emotional conflict" and "My supervisor (subordinate) and I have tension in our relationship". Cronbach's alpha for this scale was .93. To assess the level of a subordinate's perceived relationship conflict relative to his/her supervisor, we created an asymmetry measure based on suggestions from Jehn and Chapman (2000) wherein we subtracted the supervisor's score from the subordinate's score. Following Jehn et al., (2010), this resulted in a directional measure such that a positive score for dyadic RCA meant that a subordinate perceived more relationship conflict in the supervisor-subordinate dyad than the supervisor and a negative score meant that a supervisor perceived more relationship conflict in the supervisor-subordinate dyad than the subordinate.

Subordinate stress. Subordinate stress was measured using Hunter and Thatcher's (2007) six-item scale of felt stress $(1=$ strongly disagree to $5=$ strongly agree $)$. Sample items are "My job gets to me more than it should" and "There are a lot of times when my job drives me right up the wall". Cronbach's alpha for this scale was .71.

Counterproductive work behaviors toward supervisor. Subordinates' counterproductive work behaviors directed towards supervisors (hereafter referred to as CWB-I) was measured using an adapted version of Dalal, Lam, Weiss, Welch \& Hulin's (2009) five-item scale. Sample items are "Behaved in an unpleasant manner towards your supervisor" and "Tried to avoid interacting with your supervisor". Items were measured on a five-point Likert scale where $(1=$ never, $2=$ rarely, $3=$ occasionally, $4=$ frequently, and $5=$ always $)$. The item "Try to harm my supervisor" was removed from the scale because of a low item-total correlation. Cronbach's alpha for this scale was .74.

Control variables. We controlled for employee gender $(0=$ male, $1=$ female $)$, location ( 0 = same location; 1 = different location) and task complexity (Pelled, Eisenhardt, \& Xin, 1999). The item for task complexity read, "The technology, required skills, or information needed in my job are constantly changing" $(1=$ strongly disagree to $5=$ strongly agree $)$. Similar to Jehn et al. (2010), we were interested in the amount of variance explained by conflict asymmetry beyond that explained by average levels of conflict. As did they, we also controlled for the mean level of relationship conflict in the supervisor-subordinate dyad by using the aforementioned adapted version of Jehn's (1995) four-item intragroup relationship conflict scale $(1=$ strongly disagree to $5=$ strongly agree $)$. This choice is also consistent with Harrison and Klein (2007) who advise that the mean level of a variable needs to be controlled when examining 
asymmetry variables in order to prevent each variable from being confounded by the other. Cronbach's alpha for this scale was .93.

\section{Results}

\section{Descriptive Statistics and Zero-Order Correlations}

The descriptive statistics and zero-order correlations for the major variables of interest in the study are provided in Table 1. Overall, the zero-order correlations support the proposed model. RCA was significantly correlated with stress, CWB-I, and turnover intentions $(r=0.16$, $p<0.05, r=0.22, p<0.05$, and $r=0.18, p<0.05$, respectively). Further, the correlations of stress and CWB-I with turnover intentions were significant $(r=0.29, p<0.01$ and $r=0.23, p<$ 0.01 , respectively). These results suggest that RCA is linearly related to stress, CWB-I, and turnover intentions. Although gender, co-location, task complexity, and mean relationship conflict were explored as control variables, only gender and mean relationship conflict was found to have an intercorrelation among some of the key variables in the study. The following analyses include control variables although a post-hoc analysis revealed exclusion of the control variables did not alter any statistical results.

\section{Data Analysis Approach}

Our hypothesized model is suggestive of partial mediation such that supervisorsubordinate RCA is directly related to subordinate turnover intentions as well as indirectly related through subordinate stress and counterproductive behaviors directed towards supervisors. Also, recall that conflict asymmetry theory suggests that differences in conflict perceptions should explain incremental variance beyond that explained by mean levels of conflict (Jehn et al., 2010). As a result, we tested the following hypotheses while controlling for mean levels of relationship conflict in the supervisor-subordinate dyad.

The study's hypothesis were tested using Structural equation modeling (SEM) in Stata 12 (Stata Technical Support, 2011) with the bootstrapping procedure, with supported hypothesis accepted at the $95 \%$ confidence level. All analyses used a covariance matrix as input and maximum likelihood estimation. We began by estimating a measurement model for the scales. We then added paths to the measurement model to test the hypothesized relationships. Finally, we estimated several alternative models to explore the model that best represented our data.

\section{Hypothesis Testing}

Next the latent structural model in Figure 1 was used to test our proposed hypotheses. First we assessed the model. Four measures of model fit were calculated: $\chi^{2,}$ comparative fit index (CFI), root-mean-square error of approximation (RMSEA), and standardized root-meansquare residual (SRMR) A non significant $\chi^{2}$ indicates good model fit; however $\chi 2$ is sensitive to sample size. A CFI value of .95 or higher, a RMSEA value of .06 or lower, and a SRMR value of .08 or lower indicate good model fit (Hu \& Bentler, 1999). Results displayed in Table 2 indicated the model fit the data $\left(\chi^{2}(1, \mathrm{n}=178)=2.62, p>0.105 ; \mathrm{CFI}=0.98\right.$; $\mathrm{RMSEA}=0.08$; $\mathrm{SRMR}=0.02$ ). As shown in Figure 2, of the five estimated structural paths, all but one (RCA to turnover intentions) was significant. 
Table 1.

Means, Standard Deviations, and Latent Variable Intercorrelations

\begin{tabular}{|c|c|c|c|c|c|c|c|c|c|c|c|c|}
\hline & Variable & $\mathbf{M}$ & SD & 1 & 2 & 3 & 4 & 5 & 6 & 7 & 8 & 9 \\
\hline 1 & Gender $^{\mathrm{a}}$ & 0.38 & 0.49 & & & & & & & & & \\
\hline 2 & Co-location & 0.86 & 0.35 & $0.19 *$ & & & & & & & & \\
\hline 3 & Task Complexity & 3.42 & 0.98 & -0.15 & $-.20 * *$ & & & & & & & \\
\hline 4 & Mean Relationship Conflict & 1.56 & 0.61 & -0.15 & -0.14 & 0.02 & & & & & & \\
\hline 5 & Relationship Conflict Asymmetry & 0.08 & 0.91 & 0.07 & 0.07 & -0.01 & 0.03 & & & & & \\
\hline 6 & Felt Stress & 2.62 & 0.95 & -0.1 & -0.11 & -0.07 & $.25 * *$ & $.16^{*}$ & & & & \\
\hline 7 & CWB-I ${ }^{b}$ & 1.46 & 0.49 & -0.13 & -0.05 & -0.06 & $.33 * *$ & $.22 *$ & $.22 * *$ & & & \\
\hline 8 & Turnover Intentions & 2.66 & 1.16 & $.21 * *$ & 0.04 & $-.23 * *$ & 0.11 & $.18^{*}$ & $.29 * *$ & $.23 * *$ & & \\
\hline 9 & Relationship Conflict-Subordinate & 1.60 & 0.77 & -0.07 & -0.07 & .01 & $.81 * *$ & $.61 * *$ & $.29 * *$ & $.39 * *$ & $.19 * *$ & \\
\hline 10 & Relationship Conflict-Supervisor & 1.52 & 0.75 & $-.16^{*}$ & $-.16^{*}$ & .02 & $.80 * *$ & $-.59 * *$ & 0.11 & 0.13 & -.02 & $.29 * *$ \\
\hline
\end{tabular}

Note.

${ }^{\mathrm{a}} 0=$ male, $1=$ female

${ }^{\mathrm{b}}$ CWB-I = Counterproductive Work Behaviors directed towards Supervisor

$* p<.05 . * * p<.01 . * * * p<.001$.

$\mathrm{n}=178$ 
Table 2

Structural Equation Modeling Results

\begin{tabular}{|c|c|c|c|c|c|c|c|c|c|c|c|c|}
\hline \multirow[b]{3}{*}{ Independent Variable } & \multicolumn{12}{|c|}{ Dependent Variable } \\
\hline & \multicolumn{4}{|c|}{ Felt Stress } & \multicolumn{4}{|c|}{ CWB-I } & \multicolumn{4}{|c|}{ Turnover Intentions } \\
\hline & $B$ & $\mathrm{SE}$ & $\mathrm{z}$ & $p$-value & $B$ & $\mathrm{SE}$ & $\mathrm{z}$ & $p$-value & $B$ & SE & $\mathrm{z}$ & $p$-value \\
\hline Gender & -0.115 & 0.144 & -0.8 & 0.422 & -0.111 & 0.071 & -1.57 & 0.116 & 0.547 & 0.163 & 3.35 & 0.001 \\
\hline Co-location & -0.194 & 0.203 & -0.96 & 0.338 & -0.027 & 0.997 & -0.27 & 0.789 & -0.019 & 0.229 & -0.08 & 0.933 \\
\hline Task Complexity & 0.042 & 0.071 & 0.59 & 0.556 & -0.040 & 0.035 & -1.15 & 0.251 & -0.245 & 0.080 & -3.05 & 0.002 \\
\hline Felt Stress & & & & & & & & & 0.326 & 0.085 & 3.83 & 0.000 \\
\hline CWB-I & & & & & & & & & 0.375 & 0.173 & 2.16 & 0.030 \\
\hline
\end{tabular}

Note: Unstandardized coefficients are shown with standard error.

$\mathrm{RC}=$ Relationship Conflict. CWB-I = Counterproductive Work Behavior Directed Towards

Supervisor. 
In examining the hypothesized relationships demonstrated in Figure 2, hypothesis 1 posited that supervisor-subordinate RCA would be positively related to subordinate turnover intentions. As shown in Table 2, hypothesis 1 is not supported, as the path between supervisorsubordinate RCA and subordinate turnover intentions was not significant $(B=.104, \mathrm{SE}=.088, z$ $=1.18, p=.237$ ). In Hypotheses $2 \mathrm{a}$ and $3 \mathrm{a}$, we posited that supervisor-subordinate RCA would be positively associated with subordinate stress and CWB-I respectively. Hypothesis $2 \mathrm{a}$ and $3 \mathrm{a}$ are supported as supervisor-subordinate RCA was positively related to subordinate stress $(B=$ $.168, \mathrm{SE}=.075, z=2.24, p=.025)$ and subordinate counterproductive work behaviors $(B=.119$, $\mathrm{SE}=.037, z=3.23, p=.001)$. Finally, in hypotheses $2 \mathrm{~b}$ and $3 \mathrm{~b}$, we posited that subordinate stress would be positively associated with subordinate turnover intentions and that CWB-I would be positively associated with subordinate turnover intentions. Hypotheses $2 \mathrm{~b}$ and $3 \mathrm{~b}$ are supported, as there are positive, significant relationships between subordinate stress and subordinate turnover intentions $(B=.326, \mathrm{SE}=.085, z=3.83, p=.000)$ and between subordinate counterproductive work behaviors and subordinate turnover intentions $(B=.375, \mathrm{SE}$ $=.173, z=2.16, p=.030)$.

\section{Alternative Model Testing}

Although our model was theoretically driven and supported by prior research, the possibility of alternative models that fit equally well exists. Thus, to insure the hypothesized parallel mediation model was the best depiction of the relationships examined, it was compared to three, theoretically rational and conceptually nested alternative models (reported in Table 3 ). In these models paths were either entered or deleted. Because these models were nested within the revised, partially mediated model, we were able to examine the differences in model fit with a $\chi^{2}$ difference test.

In the first alternative model, we relaxed the direct path from supervisor-subordinate RCA to subordinate turnover intentions. This model tested whether subordinate stress fully mediated the relationship between supervisor-subordinate RCA and subordinate turnover intentions and whether subordinate counterproductive work behaviors fully mediated the relationship between supervisor-subordinate RCA and subordinate turnover intentions. In comparisons of full or partially mediated models, evidence of mediation is established when a partially mediated model does not provide a significant improvement in fit over the more parsimonious fully mediated model (Kelloway, 1995), and parsimonious models are used as the theoretical baselines because they are the easiest to reject (James, Mulaik, \& Brett, 2006; Mulaik, 2002). Given that the partial mediation model is nested within the full mediation model, the significance test of the additional linkage is based on a difference chi-square statistic (Maruyama, 1998). Upon investigation, this model was found to have an overall good fit $\left(\chi^{2}(2, \mathrm{n}\right.$ $=178)=4.01, p>0.134$; CFI $=0.98$; RMSEA = 0.08; SRMR = 0.02). However, the fit between the hypothesized model and the full mediation model is non-significant $\left(\Delta \chi^{2}=1.39, \Delta d f=1, p=\right.$ 0.238). Therefore, the additional path in the hypothesized model is not supported, and the hypothesized model is rejected in favor of alternative model 1 , which supports full mediation. 


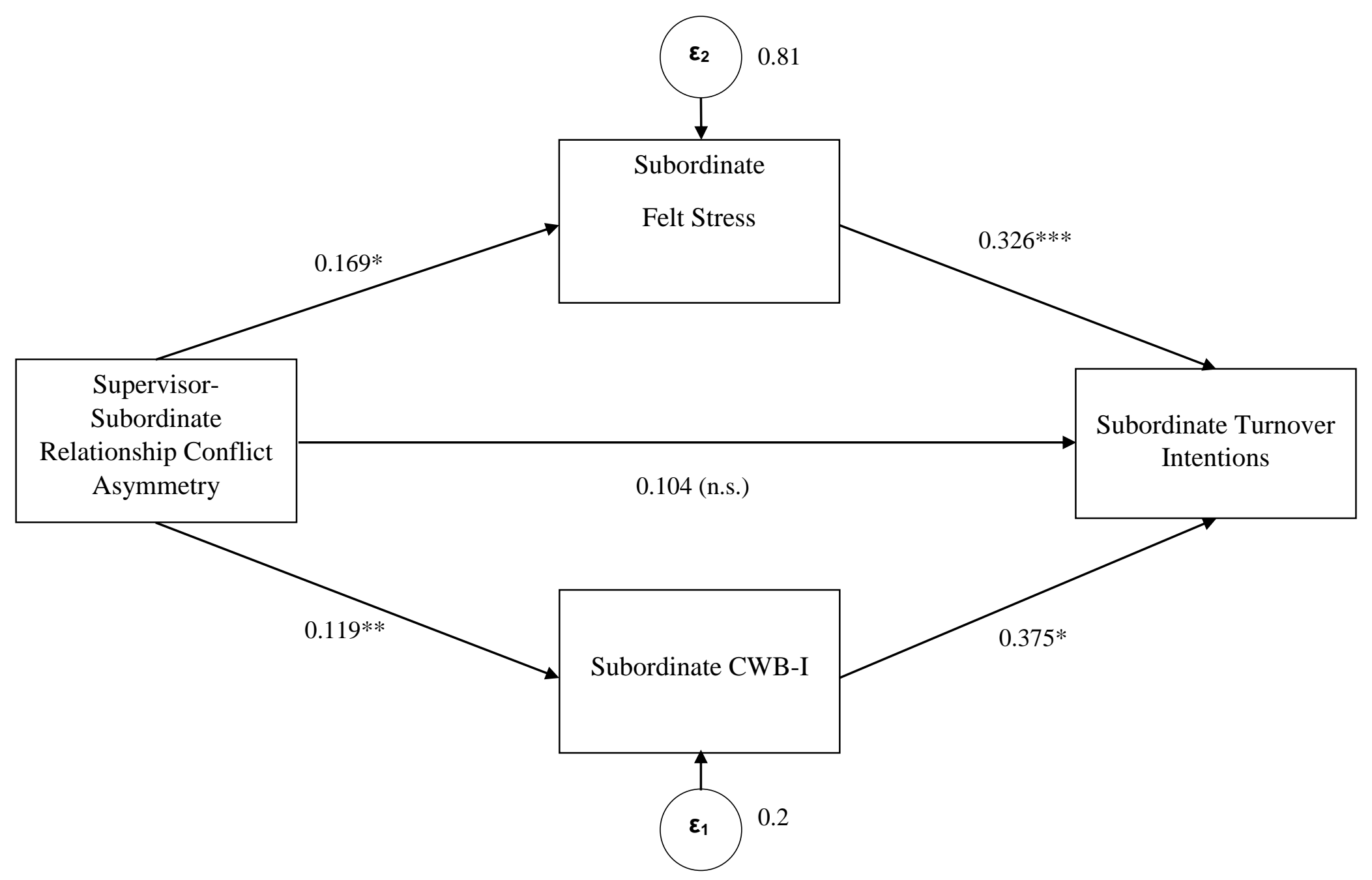

Figure 2. Unstandardized Path Loadings

$* p<.05 . * * p<.01 . * * * p<.001$. 
Table 3.

Alternative Model Test Results

\begin{tabular}{|c|c|c|c|c|c|c|c|c|c|}
\hline \multirow[b]{2}{*}{ Model } & \multicolumn{2}{|c|}{ Information Criteria } & \multirow[b]{2}{*}{$\chi^{2}$} & \multirow[b]{2}{*}{$d f$} & \multirow[b]{2}{*}{$\Delta \chi^{2}$} & \multirow[b]{2}{*}{$\Delta d f$} & \multirow[b]{2}{*}{ CFI } & \multirow[b]{2}{*}{ RMSEA } & \multirow[b]{2}{*}{ SRMR } \\
\hline & $\begin{array}{l}\text { Akaike } \\
\text { (AIC) }\end{array}$ & Bayesian (BIC) & & & & & & & \\
\hline Hypothesized (see Figure 1) & 2897.92 & 2990.19 & 2.62 & 1 & & & 0.98 & 0.08 & 0.02 \\
\hline $\begin{array}{l}\text { Alternative 1: Full Mediation } \\
\mathrm{RCA} \rightarrow \mathrm{TI} \text { (path relaxed) }\end{array}$ & 2897.32 & 2986.41 & 4.02 & 2 & 1.39 & 1 & 0.98 & 0.08 & 0.02 \\
\hline $\begin{array}{l}\text { Alternative } 2 \text { Serial Multiple } \\
\text { Mediation } \\
\text { Stress } \rightarrow \text { CWB-I (path added) }\end{array}$ & 2896.69 & 2988.96 & 1.39 & 1 & 1.23 & 0 & 0.99 & 0.05 & 0.01 \\
\hline $\begin{array}{l}\text { Alternative 3: Full Serial } \\
\text { Mediation } \\
\mathrm{RCA} \rightarrow \text { Stress } \rightarrow \text { CWB-I } \rightarrow \text { TI }\end{array}$ & 2916.54 & 3002.45 & 25.24 & 3 & 22.62 & 1 & 0.72 & 0.20 & 0.05 \\
\hline
\end{tabular}


To provide additional evidence of our results we used the Akaike Information Criterion (AIC; Akaike, 1973) and Bayesian Information Criterion (BIC; Schwarz, 1978). The AIC and BIC are indices computed from the likelihood of seeing a model given the data rewarded by goodness of fit and penalized for lack of parsimony (Burnham \& Anderson, 2004). The model with the smallest AIC and BIC values is considered the optimal choice among the alternatives. The results of these two criteria suggested alternative model 1 exhibited overall better fit than the hypothesized model.

As part of our next alternative model, we relaxed the direct path from supervisor-subordinate RCA to subordinate turnover intentions. Additionally, we entered a direct path from subordinate stress to subordinate counterproductive work behavior. The revised serial multiple mediation model (alternative model 2) was found to have an overall good fit $\left(\chi^{2}(1, \mathrm{n}=178)=1.39, p>\right.$ $0.238 ; \mathrm{CFI}=0.99 ; \mathrm{RMSEA}=0.05 ; \mathrm{SRMR}=0.01$ ). However, the significance of difference in fit between the hypothesized model and alternative model 2 cannot be determined as the models are mathematically equivalent. Therefore, the additional path in the model is considered theoretically sound as with the hypothesized model.

For our final alternative model, it is possible that the effects of supervisor-subordinate conflict asymmetry follow a full serial mediation model such that the stressor (conflict asymmetry) leads to a psychological strain (subordinate felt stress), which then leads to a behavioral strain (subordinate CWB-I), which leads to an affective strain (subordinate turnover intentions). To test this alternative, we relaxed the direct path(s) from supervisor-subordinate RCA to subordinate turnover intentions and from supervisor-subordinate RCA to subordinate counterproductive work behaviors. Additionally, we relaxed the direct path from subordinate stress to subordinate turnover intentions to determine whether the full serial mediation model in which the effects of subordinate turnover intention from supervisor-subordinate RCA are fully mediated through subordinate stress and counterproductive work behavior is the best representation of our data. The removal of these paths resulted in a significant reduction in model fit $\left(\chi^{2}(3, \mathrm{n}=178)=25.24, p>0.000 ; \mathrm{CFI}=0.72 ; \mathrm{RMSEA}=0.20 ; \mathrm{SRMR}=0.05\right)$.

Next, we used the results of our alternative models to determine whether full or partial mediation was the best representation of our data. Our results suggest that the full mediation model (alternative model 1) was the most parsimonious and resulted in the best overall fit and the best representation of our data as the chi-square difference between the fully mediated model and the partially mediated model was not significant and the additional path was not significant. Therefore, we used this more parsimonious and fully mediated model to explore the indirect effects found in our model.

Finally, we conducted the alternative test, which involves bootstrapping the sampling distribution of the mediated effect. The indirect of effect of supervisor-subordinate RCA on subordinate turnover intentions through subordinate stress was 0.06 . In addition, the indirect of effect of supervisor-subordinate RCA on subordinate turnover intentions through subordinate counter productive work behaviors was 0.06 . Viewed as a whole, our results provide support for hypothesis $2 \mathrm{c}$, as the relationship between supervisor-subordinate RCA and subordinate turnover intention is fully mediated by subordinate stress. Further, support was found for hypothesis $3 c$ as 
supervisor-subordinate RCA and subordinate turnover intentions was fully mediated by subordinate counter productive work behavior.

\section{Discussion}

In the current study, we found support for a relationship between supervisor-subordinate RCA and subordinate turnover intentions mediated by the collective influence of subordinate felt stress and CWB-I. Our findings demonstrate the usefulness of situating supervisor-subordinate conflict asymmetries in a stressor-to-strain-to-turnover framework (de Croon et al, 2004). Results confirm expectations of COR theory suggesting that subordinate underestimation is a stressful condition that threatens and depletes subordinates' resources. Further, the effects of subordinate overestimation of conflict on subordinate turnover intentions are transmitted through its impact on subordinates' psychological strain (felt stress) and behavioral strain (CWB-I). With this, our study makes a number of contributions.

First, we extend the current focus of conflict asymmetry theory from perceptions of intragroup conflict to self-other perceptions of conflict in supervisor-subordinate dyads. Second, this shift allowed us to draw on and contribute to existing supervisor-subordinate agreement research which has focused primarily on supervisor-subordinate agreement regarding LMX quality (Cogliser et al., 2012) and affective commitment (Landry et al., 2014), but not relationship conflict. Third, we contribute to the organizational stress literature by being among the few studies to use COR theory to situate CWB-I in a larger model of stressors, strains and turnover (Penny et al., 2011). Fourth, consistent with the approach taken by Jehn and colleagues (2010), we demonstrate that magnitude of conflict asymmetry explains incremental variance over traditional treatments of mean levels of conflict only. As argued by Jehn and colleagues (2010):

Moreover, research has shown that when members agree on the quality of social interaction, even if they agree on a negative assessment, they produce higher-quality work (Mason \& Griffin, 2003). Therefore, it is better to agree on the level of conflict or competition in a group than to have differing viewpoints on what is occurring in the group regarding this process. (p. 599)

In this way, we add more nuance to how the quality of a supervisor-subordinate relationship influences subordinate outcomes (Dulebohn et al., 2011). Jehn et al. (2010) hypothesized supervisors who were not aware of differences in conflict perceptions among group members would experience negative consequences. Our results suggest that supervisors should not only be aware of differences in conflict perceptions among group members, but also between themselves and those they lead. By being unaware of or ignoring differences in conflict perceptions between themselves and their subordinates, supervisors may cause undue stress on subordinates and lead subordinates to direct CWBs towards them, both of which may drain subordinate resources and lead subordinates to seek employment elsewhere.

\section{Managerial Implications}

This research provides a comprehensive examination of the impact of supervisorsubordinate relationship conflict asymmetry on subordinate turnover intentions and sheds light 
on this understudied phenomenon. As such, we believe our results have a variety of meaningful managerial implications. Our findings suggest that supervisors who potentially underestimate their subordinates' perceptions of relationship conflict or ignore them may increase subordinate stress. Stress can be costly to organizations, as it has been found to be associated with decreased loyalty, increased job search, and increased turnover intentions (Boswell et al., 2004). In addition, supervisors make themselves targets for counterproductive work behaviors, and these behaviors are costly to organizations (Pearson \& Porath, 2009). We predicted and found support that both would increase subordinate turnover intentions. Subordinates who actually turnover can substantially reduce the benefits of stable relationships within organizations (Dess \& Shaw, 2001; Leana \& van Buren, 1999). Accordingly, supervisors committed to minimizing subordinate distress, dissatisfaction, and turnover should be vigilant concerning maintaining awareness of their subordinates' feelings concerning incompatibilities and disagreements. Regardless of the amount of conflict perceived, our findings support the notion that "agreeing to disagree" is superior to having disagreements about disagreement.

Moreover, we find that the relationship between supervisor-subordinate relationship conflict asymmetry is not direct but rather follows an emotional process which highlights the need for supervisors to be conscious of the perceived conflict and help manage the resources that are depleted by their subordinates leading to stress and feelings of counterproductive work behaviors. Supervisors would want to acknowledge the signs from their subordinates or engage in communication that would make them aware of the current state of affairs. Supervisors can insure that lines of communication are open for subordinates and allow subordinates to share important workplace concerns that could alleviate conflict. It is evident from this study that differences in perceived relationship conflict has an impact on the experiences of subordinates and are manifested through stress, inappropriate workplace behaviors, and feelings of leaving the organization. Thus, when supervisors are aware that employees are experiencing stress or engaging in certain behaviors he/she should actively seek to open the communication channels and aid the employee through the situation, which could result in reduced thoughts of exiting the organization.

\section{Limitations and Directions for Future Research}

Despite several strengths of the current investigation, it is not without limitations. First, the cross-sectional nature of our study design prohibited inferences regarding causality. It is possible that subordinates may have developed turnover intentions for reasons other than those in this study. For example, prior research indicates an organization's employment practices are associated with turnover (Arthur, 1994; Batt \& Colvin, 2011; Huselid, 1995). These other reasons may lead subordinates to feel increased stress and urges to engage in CWB-I. These reactions could lead to subordinates' overestimations regarding the true amount of conflict in the relationship. Future research should endeavor to disentangle these nuances. Relatedly, we did not measure whether subordinates actually quit their organizations at a later point in time. Only a longitudinal design would allow us to determine whether turnover intentions resulted in actual turnover.

Next, previous research suggests that gender differences may cause or increase the negative impact of conflict (Pelled et al., 1999). Although gender was only a control variable in 
this study, our analyses indicate that gender was significantly related to our variables of interest. Females appear to be more sensitive to conflict asymmetry with their supervisors than males. This finding suggests that a closer investigation of gender differences may reveal boundary conditions on the model advanced in our study. Moreover, conflict associated with other lines of difference such as those based on differences in race, age, and ethnicity may have an amplifying effect on conflict and turnover intentions. Relatedly, we are unable to rule out the possibility that endogeneity may be a driver of the effects observed in this research. For example, although other forms of conflict such as disagreements based on division of labor and allocation resources (i.e. process conflicts) were not captured in this study, they may account for unobserved variance between our variables of interest. Future research would do well to explore the extent to which conflict asymmetry is driven by factors such as demographic diversity or the type of conflict being experienced.

Although we make arguments regarding the investment of resources in accordance with the level of conflict perceived, we provide no guidance regarding the types of resources contributed or conserved by supervisors and subordinates. Further, we wonder if asymmetries in perceptions of power or psychological safety impact willingness or perceived ability to invest or preserve resources. Another limitation involves our investigation of turnover intentions without capturing actual turnover. Future research should explore moderators that detail the conditions in which conflict asymmetry leads to actual turnover via turnover intentions.

Lastly, our findings using a sample of working graduate students may not be generalizable to those derived from other populations. For example, it is possible that employees in our sample who were experiencing conflict with their supervisors may have been pursuing graduate studies to support an exit strategy. It is also possible that our respondents may have been enrolled in graduate school to improve their conflict management skills or to increase their attractiveness for new roles. We encourage future researchers to explore potential boundary conditions of our model by using graduate school enrollment as a moderator.

Our research also has implications for conflict management strategies employed by supervisors and subordinates. For example, one could argue that conflict management strategies moderate the impact of conflict asymmetry on individual outcomes such as turnover intentions. Finally, we used a sample of working graduate students. Because the workers in our sample were pursuing a graduate education, they are likely to be more educated than a large portion of the workforce. Thus, these workers may have had higher-level positions than one would expect using a random sample of workers. This may cause these workers to have qualitatively different forms of relationship conflict than workers at lower-levels. We therefore encourage future research to use a more diverse sample of workers in order to assess the external validity of our findings.

\section{Conclusion}

In conclusion, the present study provides a process view and sheds new light on the supervisor-subordinate conflict and subordinate turnover intentions relationship. This research demonstrates this process using a matched supervisor-subordinate data set and helps to explain why future research should be undertaken to explore other relationships influenced by 
supervisor-subordinate relationship conflict. The findings support the notion that the more distal behavioral outcome of turnover intention may be better understood by exploring stressors and strains and other emotional processes of individuals in the workplace.

\section{References}

Akaike, H. (1973). Information theory and an extension of the maximum likelihood principle. In S. Kotz, \& N. L. Johnson (Eds.), Breakthroughs in statistics (pp. 559-624). New York: Springer.

Arthur, J. B. (1994). Effects of human resource systems on manufacturing performance and turnover. Academy of Management Journal, 37(3), 670-687.

Atwater, L. E., \& Yammarino, F. J. (1997). Self-other rating agreement: A review and model. In $\mathrm{G}$. Ferris (Ed.), Research in personnel and human resources management (Vol. 15) (pp. 121-174). United States: Elsevier Science/JAI Press.

Batt, R., \& Colvin, A. J. S. (2011). An employment system approach to turnover: human resources practices, quits, dismissals, and performance. Academy of Management Journal, 54(4), 695-717.

Beehr, T. A., Jex, S. M., Stacy, B. A., \& Murray, M. A. (2000). Work stressors and coworker support as predictors of individual strain and job performance. Journal of Organizational Behavior, 21(4), 391-405.

Begley, T. M., \& Czajka, J. M. (1993). Panel analysis of the moderating effects of commitment on job satisfaction, intent to quit and health following organizational change. Journal of Applied Psychology, 78, 552-556.

Blau, P. M. (1964). Exchange and power in social life. New York: John Wiley.

Boswell, W.R., Olson-Buchanan, J. B, \& LePine, M. A. (2004). Relations between stress and work outcomes: The role of felt challenge, job control, and psychological change, Journal of Vocational Behavior, 64, 165-181

Burnham, K. P., \& Anderson, D. R. (2004). Multimodel inference: Understanding AIC and BIC in model selection. Sociological Methods and Research, 33, 261-304.

Carver, C. S., \& Harmon-Jones, E. (2009). Anger is an approach related affect: Evidence and implications. Pscyhological Bulletin, 135, 183-204.

Cogliser, C. C., Schriesheim, C. A., Scandura, T. A., \& Gardner, W. L. (2009). Balance in leader and follower perceptions of leader-follower exchange: Relationships with performance and work attitudes. The Leadership Quarterly, 20(3), 452-465.

Croson, R., \& Donohue, K. (2006). Behavioral causes of the bullwhip effect and the observed value of inventory information. Management Science, 52, 323-336.

Dalal, R. S., Lam, H., Weiss, H. M., Welch, E. R., \& Hulin, C.L. (2009). A within-subordinate approach to work behavior and performance: Concurrent and lagged citizenshipcounterproductivity associations, and dynamic relationships with affect and overall job performance. Academy of Management Journal, 52(5), 1051-1066.

Dess, G. G, \& Shaw, J. D. (2001). Voluntary turnover, social capital, and organizational performance. Academy of Management Review, 26(3), 446-456.

De Croon, E. M., Sluiter, J. K., Blonk, R. W. B., Broersen, J. P. J., \& Frings-Dresen, M. H. W. (2004). Stressful work, psychological job strain, and turnover: A 2-year prospective cohort study of truck drivers. Journal of Applied Psychology, 89(3), 442-454. 
De Dreu, C. K. W., \& Weingart, L. R. (2003). Task versus relationship conflict, team performance, and team member satisfaction: A meta-analysis. Journal of Applied Psychology, 88, 741-749.

De Wit, F. R. C., Greer, L. L., \& Jehn, K. A. (2012). The paradox of intragroup conflict: A metaanalysis. Journal of Applied Psychology, 97, 360-390.

Deutsch, M. (1949). An experimental study of the effects of co-operation and competition upon group process. Human Relations, 2(3), 199-231.

Dulebohn, J. H., Bommer, W. H., Liden, R. C., Brouer, R. L., \& Ferris, G. R. (2011). A metaanalysis of antecedents and consequences of leader-member exchange: Integrating the past with an eye toward the future. Journal of Management, 38(6), 1715-1759.

Felson, R. B. (1984). The effect of self-appraisals of ability on academic performance. Journal of Personality and Social Psychology, 47(5), 944-952.

Frone, M. R. (2000). Interpersonal conflict at work and psychological outcomes: Testing a model among young workers. Journal of Occupational Health Psychology, 5(2), 246-255.

Gouldner, A. W. (1960). The norm of reciprocity: A preliminary statement. American Sociological Review, 25(2), 161-178.

Graen, G. B., \& Uhl-Bien, M. (1995). Relationship-based approach to leadership: Development of Leader-Member Exchange (LMX) Theory of leadership over 25 years: Applying a multi-level multi-domain perspective. The Leadership Quarterly, 6(2), 219-247.

Grandey, A. A., \& Cropanzano, R. (1999). The conservation of resources model applied to workfamily conflict and strain. Journal of Vocational Behavior, 54, 350-370.

Greenberg, J. (1990). Organizational justice: yesterday, today, and tomorrow. Journal of Management, 16(2), 399-432.

Halbesleben, J. R. B., \& Bowler, W. M. (2007). emotional exhaustion and job performance: The mediating role of motivation. Journal of Applied Psychology, 92(1), 93-106.

Halbesleben, J. R., Harvey, J., \& Bolino, M. C. (2009). Too engaged? A conservation of resources view of the relationship between work engagement and work interference with family. Journal of Applied Psychology, 94(6), 1452-1456.

Harrison, D. A, \& Klein, K. J. (1997). What's the difference? Diversity constructs as separation, variety, or disparity in organization. Academy of Management Review, 32(4), 1198-1228.

Hobfoll, S. E. (1989). Conservation of resources: A new attempt at conceptualizing stress. American Psychologist, 44, 513-524.

Hu, L., \& Bentler, P. M. (1999). Cutoff criteria for fit indexes in covariance sturcture analysis: Conventional criteria versus new alternatives. Structural Equation Modeling: A Multidisciplinary Journal, 6(1), 1-55.

Hunter, L. W., \& Thatcher, S. M. B. (2007). Feeling the heat: Effects of stress, commitment, and job experience on performance. Academy of Management Journal, 50(4), 953-968.

Huselid, M. A. (1995). The impact of human resource management practices on turnover, productivity, and corporate financial performance. Academy of Management Journal, 38(3), 635-672.

Ismail, K. M., Richard, O. C., \& Taylor, E. C. (2012). Relationship conflict in leader- follower dyads: A follower perspective. International Journal of Conflict Management, 23(2), 192-218.

James, L. R., Mulaik, S. A., \& Brett, J. M. (2006). A tale of two methods. Organizational Research Methods, 9(2), 233-244. 
Jehn, K. A. (1995). A multimethod examination of the benefits and detriments of intragroup conflict. Administrative Science Quarterly, 40, 256-282.

Jehn, K., \& Bendersky, C. (2003). Intragroup conflict in organizations: A contingency perspective on the conflict-outcome relationship. Research in Organizational Behavior, 25, 187-242

Jehn, K., \& Chapman, J. A. (2000). The influence of proportional and perceptional conflict composition on team performance. International Journal of Conflict Management, 11, 56-73.

Jehn, K., Rispens, S., \& Thatcher, S. (2010). The effects of conflict asymmetry on work group and individual outcomes. Academy of Management Journal, 53, 596-616.

Kacmar, K. M., Bachrach, D. G., Harris, K. J., \& Noble, D. (2012). Exploring the role of supervisor trust in the associations between multiple sources of relationship conflict and organizational citizenship behavior. The Leadership Quarterly, 23(1), 43-54.

Kelloway, E. K. (1995). Structural equation modeling in perspective. Journal of Organizational Behavior, 16, 215-224.

Korsgaard, M. A., Soyoung Jeong, S., Mahony, D. M., \& Pitariu, A. H. (2008). A multilevel view of intragroup conflict. Journal of Management, 34, 1222-1252.

Labianca, G., \& Brass, D. J. (2006). Exploring the social ledger: Negative relationships and negative asymmetry in social networks in organizations. Academy of Management Review, 31(3), 596-614.

Landry, G., \& Vandenberghe, C. (2009). Role of commitment to the supervisor, leader-member exchange, and supervisor-based self-esteem in employee-supervisor conflicts. The Journal of Social Psychology, 149(1), 5-28.

Leana, C. R, \& Van Buren, H. J. (1999). Organizational social capital and employment practices. Academy of Management Review, 24(3), 538-555.

Lepine, J. A., Podsakoff, N. P., \& Lepine, M. A. (2005). A meta-analytic test of the challenge stressor-hindrance stressor framework: An explanation for inconsistent relationships among stressors and performance. Academy of Management Journal, 48(5), 764-775.

Maertz, C. P., \& Griffeth, R. W. (2004). Eight motivational forces and voluntary turnover: A theoretical synthesis with implications for research. Journal of Management, 30(5), 667683.

Maruyama, G. M. (1998). Basics of structural equation modeling. Thousand Oaks, CA: Sage.

Milliken, F. J., (1990). Perceiving and interpreting environmental changes: An examination of college administrators' interpretation of changing demographics. Academy of Management Journal, 33, 42-63.

Morrison, E. W., \& Robinson, S. L. (1997). When employees feel betrayed: A model of how psychological contract violation develops. Academy of Management Review, 22(1), 226256.

Mulaik, S. A. (2002). The curve-fitting problem: An objectivist view. Philosophy of Science, 68, 218-241.

Murray, S. L., Holmes, J. G., \& Griffin, D. W. (1996). The benefits of positive illusions: Idealization and the construction of satisfaction in close relationships. Journal of Personality and Social Psychology, 70, 79-98.

Organ, D. W. (1990). The motivational basis of organizational citizenship behavior. In B. M. Staw, \& L. L. Cummings (Eds.), Research in organizational behavior (Vol. 12) pp. (4372). Greenwich, CT: JAI Press. 
Pearson, C, \& Porath, C (2009). The cost of bad behavior: how incivility is damaging your business and what to do about it. New York: Penguin Group.

Pelled, L. H., Eisenhardt, K. M., \& Xin, K. R. (1999). exploring the black box: An analysis of work group diversity, conflict, and performance. Administrative Science Quarterly, 44, 128.

Penney, L. M., Hunter, E. M., \& Perry, S. J. (2011). Personality and counterproductive work behaviour: Using conservation of resources theory to narrow the profile of deviant employees. Journal of Occupational and Organizational Psychology, 84(1), 58-77.

Pondy, L. R. (1967). Organizational conflict: Concepts and models. Administrative Science Quarterly, 12, 296-320.

Podsakoff, P. M, MacKenzie, S. B, Lee, J., \& Podsakoff, N. P. (2003). Common method biases in behavioral research: A critical review of the literature and recommended remedies. Journal of Applied Psychology, 88(5), 879-904.

Rispens, S., Greer, L., Jehn, K. A., \& Thatcher, S. M. B. (2011). Not so bad after all: How relational closeness buffers the association between relationship conflict and helpful and deviant group behaviors. Negotiation and Conflict Management Research, 4(4), 277-296.

Robinson, S. L., \& Morrison, E. W. (2000). The development of psychological contract breach and violation: A longitudinal study. Journal of Organizational Behavior, 21(5), 525-546.

Rosenthal, R., \& Rosnow, R. L. (2006). Essentials of behavioral research: Methods and data analysis. New York: McGraw-Hill.

Schwarz, G. (1978). Estimating the dimension of a model. Annals of Statistics, 6, 461-464.

Shanock, L. R, Baran, B. E, Gentry, W. A, Pattison, S. C, \& Heggestad, E. D. (2010). Polynomial regression with response surface analysis: A powerful approach for examining moderation and overcoming limitations of different scores. Journal of Business and Psychology, 25(4), 543-554.

Shaw, J. D., Zhu, J., Duffy, M. K., Scott, K. L., Shih, H., \& Susanto, E. (2011). A contingency model of conflict and team effectiveness. Journal of Applied Psychology, 96, 391-400.

Sliter, M., Sliter, K., \& Jex, S. (2012). The employee as a punching bag: The effect of multiple sources of incivility on employee withdrawal behavior and sales performance. Journal of Organizational Behavior, 33(1), 121-139.

Spector, P. E., \& Jex, S. M. (1998). Development of four self-report measures of job stressors and strain: Interpersonal conflict at work scale, organizational constraints scale, quantitative workload inventory, and physical symptoms inventory. Journal of Occupational Health Psychology, 3(4), 356-367.

StataCorp. (2011). Stata Statistical Software: Release 12. College Station, TX: StataCorp.

Staw, B. M., Sandelands, L. E., \& Dutton, J. E. (1981). Threat rigidity effects in organizational behavior: A multilevel analysis. Administrative Science Quarterly, 26, 501-524.

Taylor, S. E., \& Brown, J. D. (1988). Illusion and well-being: A social psychological perspective on mental health. Psychological Bulletin, 103(2), 193-210.

Tepper, B. J., \& Taylor, E. C. (2003). Relationships among supervisors' and subordinates' procedural justice perceptions and organizational citizenship behaviors. Academy of Management Journal, 45, 97-105.

Van Dyne, L., Jehn, K. A., \& Cummings, A. (2002). Differential effects of strain on two forms of work performance: Individual employee sales and creativity. Journal of Organizational Behavior, 23(1), 57-74. 
Wheeler, A. R., Harris, K. J., \& Sablynski, C. J. (2012). How do employees invest abundant resources? The mediating role of work effort in the job-embeddedness/job-performance relationship. Journal of Applied Social Psychology, 42, E244-E266.

Xin, K. R., \& Pelled, L. H. (2003). Supervisor-subordinate conflict and perceptions of leadership behavior: a field study. Leadership Quarterly, 14(1), 25-40

Yammarino, F. J., \& Atwater, L. E. (1997). Do managers see themselves as others see them? Implications of self-other rating agreement for human resources management. Organizational Dynamics, 25(4), 35-44. 